\title{
Stress hormones concentrations in the normal microenvironment predict risk for chemically induced cancer in rats
}

\author{
Vitor Bonetti Valente ${ }^{\mathrm{a}}$, Flávia Alves Verza ${ }^{\mathrm{a}}$, Felipe Yudi Kabeya Lopes ${ }^{\mathrm{a}}$, Joana Zafalon Ferreira ${ }^{\mathrm{b}}$, \\ Paulo Sérgio Patto dos Santos ${ }^{\mathrm{b}}$, Maria Lúcia Marçal Mazza Sundefeld ${ }^{\mathrm{c}}$, Éder Ricardo Biasoli ${ }^{\mathrm{a}, \mathrm{d}}$, \\ Glauco Issamu Miyahara ${ }^{\mathrm{a}, \mathrm{d}}$, Ana Maria Pires Soubhia ${ }^{\mathrm{d}}$, Mariza de Andrade ${ }^{\mathrm{e}}$, \\ Sandra Helena Penha de Oliveira ${ }^{\mathrm{f}}$, Daniel Galera Bernabé ${ }^{\mathrm{a}, \mathrm{d}, *}$
}

a Psychoneuroimmunology Research Center, Oral Oncology Center, São Paulo State University (Unesp), School of Dentistry, 1193 José Bonifácio St., SP 15050-015, Araçatuba, São Paulo, Brazil

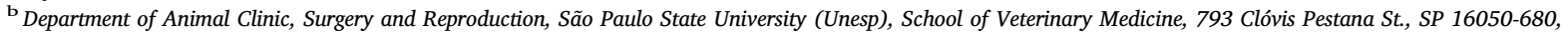
Araçatuba, São Paulo, Brazil

${ }^{\mathrm{c}}$ Department of Statistics, Oral Oncology Center, São Paulo State University (Unesp), School of Dentistry, 1193 José Bonifácio St., SP 15050-015, Araçatuba, São Paulo, Brazil

' Department of Pathology and Clinical Propedeutics, São Paulo State University (Unesp), School of Dentistry, 1193 José Bonifácio St., SP 15050-015, Araçatuba, São Paulo, Brazil

e Department of Biomedical Statistics and Informatics, Mayo Clinic College of Medicine, 200 First St. SW, MN 55905, Rochester, MN, USA

${ }^{\mathrm{f}}$ Immunopharmacology Laboratory, Department of Basic Sciences, São Paulo State University (Unesp), School of Dentistry, 1193 José Bonifácio St., SP 15050-015,

Araçatuba, São Paulo, Brazil

\section{A R T I C L E I N F O}

\section{Keywords:}

Cancer

Carcinogenesis

Stress hormones

BDNF

Oral cancer

\begin{abstract}
A B S T R A C T
Evidence show that stress hormones can influence cancer progression, but its role in carcinogenesis is poorly understood. In this study, we used a new method based on oral carcinogenesis model in rats to test the hypothesis that physiological levels of stress hormones in the normal tissue microenvironment would have significant predictive value for chemically induced cancer occurrence. Male Wistar rats were submitted to a tongue biopsy for measuring not-stress induced levels of norepinephrine, corticosterone, adrenocorticotropic hormone (ACTH) and brain-derived neurotrophic factor (BDNF) in the tissue before carcinogenic induction. Rats were treated with the 4-nitroquinoline-1-oxide (4NQO) chemical carcinogen for twenty weeks and then euthanized for microscopic evaluation of the tongue lesions. Increased pre-carcinogen norepinephrine concentrations and reduced basal corticosterone levels in the normal tissue microenvironment were predictive for oral squamous cell carcinoma (OSCC) occurrence. Likewise, increased pre-carcinogen norepinephrine levels in the normal microenvironment were associated a lower expression of pCDKN2a-p16 in OSCCs. Post-carcinogen levels of corticosterone and BDNF in oral leukoplakia tissues (precursor lesion of OSCC) and post-carcinogen corticosterone concentrations in OSCCs were higher than basal levels in the normal mucosa. Increased norepinephrine concentrations in OSCCs were associated to a greater tumor volume and thickness. Furthermore, higher levels of norepinephrine, ACTH and BDNF in OSCCs were associated to a lesser intensity of the lymphoplasmocytic infiltrate. This study shows that pre-carcinogen stress hormones levels in the normal microenvironment may be predictive for chemically induced cancer in rats. Moreover, chemical carcinogenesis can promote stressor-like effects with hormonal changes in the tissue microenvironment, which may be associated to tumor progression.
\end{abstract}

\section{Introduction}

Studies have shown that hormones derived from chronic stress can influence cancer progression (Antoni et al., 2006; Reiche et al., 2004). The two main pathways that have been investigated for mediating the effects of emotional stress on cancer are the hypothalamic-pituitaryadrenal (HPA) axis and the sympathetic nervous system (SNS) (Antoni et al., 2006; Reiche et al., 2004). HPA axis activation occurs when neurons of the paraventricular nucleus secrete corticotropin-releasing factor (CRF); in sequence, CRF stimulates adrenocorticotropic hormone

\footnotetext{
* Corresponding author at: Psychoneuroimmunology Research Center, Oral Oncology Center, Department of Pathology and Clinical Propedeutics, São Paulo State University (Unesp), School of Dentistry, 1193 José Bonifácio St., SP 15050-015, Araçatuba, São Paulo, Brazil.

E-mail address: danielbernabe@foa.unesp.br (D.G. Bernabé).
} 
(ACTH) secretion from anterior pituitary gland, which induces cortisol release from adrenal gland (Antoni et al., 2006). In parallel, SNS activation can induce a deregulated production of the catecholamines norepinephrine and epinephrine by the central nervous system (CNS) and adrenal gland (Antoni et al., 2006).

Stress hormones increase the tumor production of pro-inflammatory cytokines, chemokines and growth factors affecting cancer progression (Antoni et al., 2006; Reiche et al., 2004). Stress levels of norepinephrine and epinephrine, per example, enhance the gene expression of vascular endothelial growth factor (VEGF) (Lutgendorf et al., 2003; Thaker et al., 2006) and interleukin-6 (IL-6) (Bernabé et al., 2011; Lutgendorf et al., 2008b; Nilsson et al., 2007), molecules that increase angiogenesis and cancer cell proliferation, respectively. Likewise, these hormones deregulate the production of matrix metalloproteinases (MMPs) types 2 and 9 (Lutgendorf et al., 2008a; Sood et al., 2006; Yang et al., 2006), proteins that enhance tumor invasion and metastasis occurrence. SNSinduced catecholamine release suppresses the responses of cytotoxic $\mathrm{T}$ lymphocytes and natural killer (NK) cells (Inbar et al., 2011). Experimental studies have demonstrated that stress hormones can affect ovarian (Lutgendorf et al., 2003; Lutgendorf et al., 2008a; Nilsson et al., 2007; Sood et al., 2006; Thaker et al., 2006), breast (Ben-Eliyahu et al., 1991), lung (Melamed et al., 2005) and colon (Lointier et al., 1992) cancer progression. Clinical investigations have shown that patients with advanced-stage ovarian (Lutgendorf et al., 2008b), colorectal (Rich et al., 2005) and head and neck (Bernabé et al., 2012) cancer have increased cortisol concentrations compared to patients with early-stage disease or healthy controls. Few studies have demonstrated that stress hormones can act on regular cells promoting cancer development (Feng et al., 2012; Flint et al., 2013). In a recent study, chronic stress promoted tumor development (lymphomas and sarcomas) in male mice by the attenuation of p53 protein levels and transcriptional activity, which were mediated by increased corticosterone levels in the serum (Feng et al., 2012).

Brain-derived neurotrophic factor (BDNF) is a neurotrophin widely expressed in the CNS, where it acts as trophic factor for dopaminergic and cholinergic neurons. Evidence have shown that BDNF expression in the CNS can be modulated by stress (Lewin and Barde, 1996). BDNF and its receptor TrkB have an important role as autocrine modulators being expressed in several tissues (Lewin and Barde, 1996). Acute or chronic stress may increase plasma BDNF levels in preclinical models (Saruta et al., 2010; Tsukinoki and Saruta, 2012). BDNF expression is associated with tumor cell proliferation and invasion (Kupferman et al., 2010; Yang et al., 2005) and has been identified in head and neck (Kupferman et al., 2010), liver (Yang et al., 2005), prostate (Bronzetti et al., 2008) and bladder (Lai et al., 2010) cancer, suggesting a role of this neurotrophin in cancer pathogenesis.

Tumor microenvironment is an aberrant tissue environment composed of tumor epithelial cells and mesenchymal cells surrounded by extracellular matrix (ECM) (Hu and Polyak, 2008). Most solid tumors are innervated by sympathetic fibers, which can release norepinephrine in the microenvironment (Saloman et al., 2016). Although evidence show that stress and its neurohormones may influence cancer progression, there are no studies that have assessed stress hormones concentrations in the tissue microenvironment before cancer occurrence and its predictive value for carcinogenesis and tumor progression. Exposure to chemical or physical carcinogens may affect important cellular metabolic functions such as the production of stress hormones (AlWadei et al., 2012; Anna et al., 2007). However, it is still unclear how carcinogens could modulate stress hormones levels in the tumor microenvironment.

In the present study, we used a preclinical oral carcinogenesis model to test the hypothesis that physiological levels of stress hormones in the normal tissue microenvironment (before tumor induction) would have predictive value for chemically induced cancer occurrence. Furthermore, clinicopathological features and tumor progression-related genes were analyzed after tumor induction.

\section{Materials and methods}

\subsection{Animals and maintenance conditions}

All procedures with animals followed the NIH Guide for the Care and Use of Laboratory Animals and were approved by the Institutional Animal Welfare Committee at the Araçatuba Dental School (São Paulo State University - Unesp, Araçatuba, Brazil). Forty-eight male Wistar rats, with 12 weeks old, weighing between 250 and $300 \mathrm{~g}$, were used for the experiments. The animals were group-housed ( 3 per cage) $(25.9 \times 47.6 \times 20.9 \mathrm{~cm}$, polypropylene), under constant room temperature (RT) $\left(25 \pm 2{ }^{\circ} \mathrm{C}\right)$, relative humidity (55 $\left.\pm 3{ }^{\circ} \mathrm{C}\right)$, lighting (12-h light-dark cycle) and received food ad libitum (Purina, Paulínia, SP, Brazil) and drinking water.

\subsection{Experimental design}

In order to assess whether stress hormones levels in the tongue microenvironment would have predictive value for chemically induced oral carcinogenesis, we used a new methodology. The experiments were divided in three steps. In phase 1 , all animals were submitted to a tissue collection for characterizing the stress hormones concentrations in the tongue microenvironment (pre-carcinogen hormonal levels). In phase 2 , these same animals were underwent to chemically induced oral carcinogenesis. In phase 3, after 20 weeks of oral carcinogenesis, all animals were euthanized for evaluation of oral cancer occurrence and stress hormones concentrations in the microenvironment (post-carcinogen hormonal levels) (Fig. 1A).

\subsection{Individual characterization of the stress hormones levels in the tongue microenvironment pre-carcinogenic induction}

\subsubsection{Anesthetic induction}

In the first phase of research, to characterize stress hormones levels in the tissue microenvironment all animals were submitted to a tongue biopsy under inhalatory anesthesia. Anesthetic induction was performed in an induction-chamber with $5 \%$ isoflurane in $100 \%$ oxygen ( $3 \mathrm{~L} / \mathrm{min}$ flow) connected to an open, non-rebreathing, circuit (Anesthesia equipment Nikkei K - Takaoka, São Paulo, SP, Brazil). After loss of muscle tone (ventral decubitus position), the animal was removed from the induction-chamber and maintained under anesthesia with an adapted face mask connected to the same induction system. Anesthetic maintenance was performed with $3 \%$ isoflurane and oxygen flow of $2 \mathrm{~L} / \mathrm{min}$ during the surgical procedure.

\subsubsection{Tongue biopsy pre-carcinogenic induction}

With the animal anesthetized, the tongue was pulled with a suture thread (Fig. 1B) and a biopsy was performed in the posterior region of the tongue dorsum with a $4 \mathrm{~mm}$ circular punch (Fig. 1C) allowing the removal of a lingual mucosa fragment (Fig. 1D). This area was chosen to measure the stress hormones concentrations, since it is the main location where the carcinomas develop in the chemical carcinogenesis model used in this study. After removing the tongue fragment, the surgical wound was sutured with 4.0 silk thread (Ethicon Johnson \& Johnson, São José dos Campos, SP, Brazil). The tissue sample was rinsed with physiological solution and stored at $-80{ }^{\circ} \mathrm{C}$ for hormones measurements. The tissue collection was always performed in the morning period between 8 am and $12 \mathrm{pm}$. During the three weeks postoperative period following tongue biopsy, the animals were fed with water-softened chow.

2.3.3. Measurements of the stress hormones concentrations in the tongue microenvironment

2.3.3.1. Sample preparation. For measuring stress hormones levels in the tongue microenvironment, the tissue samples were homogenized in a PBS buffer with a protease inhibitor cocktail (Calbiochem, San Diego, 


\begin{tabular}{|c|c|c|c|}
\hline A & & & $\begin{array}{l}\text { Tongue } \\
\text { extraction }\end{array}$ \\
\hline Adaptation & Postoperative & 4NQO carcinogen treatment & \\
\hline $\begin{array}{l}3 \text { weeks } \\
\text { Arrival }\end{array}$ & $\begin{array}{r}3 \text { weeks } \\
\text { Sta }\end{array}$ & 20 weeks & Euthanasia \\
\hline
\end{tabular}
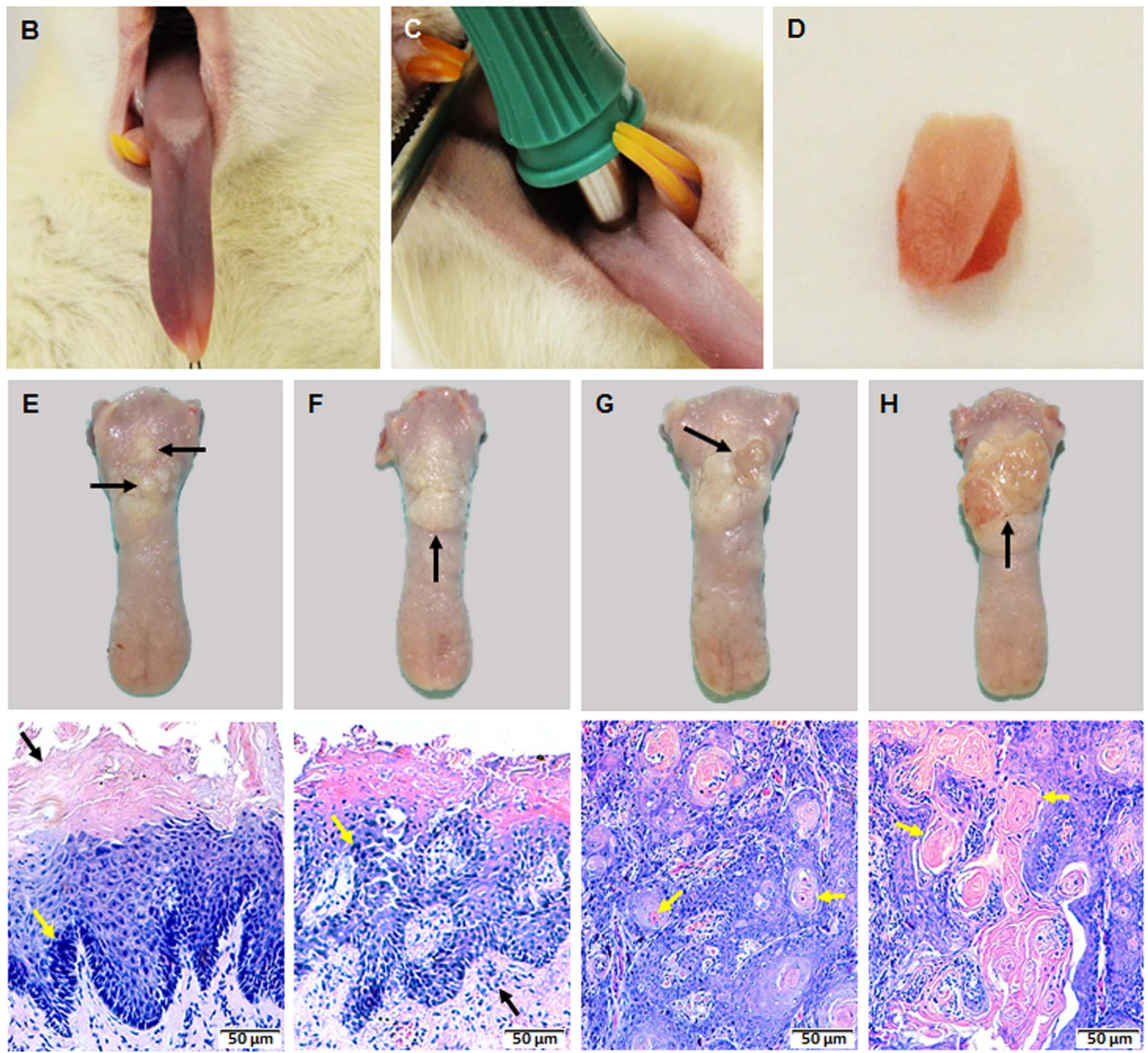

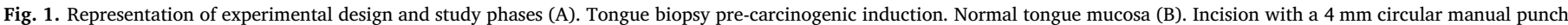

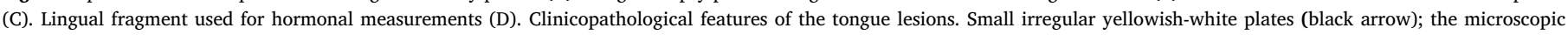

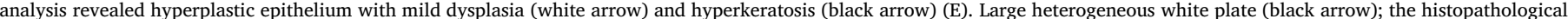

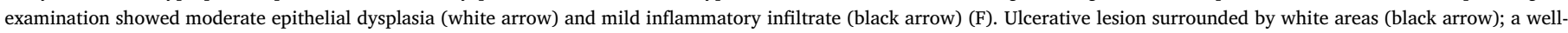

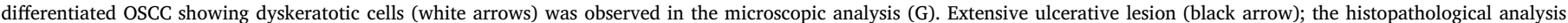
showed a well-differentiated OSCC with large keratin pearls (white arrows) (H).

CA, USA). The homogenates were centrifuged for $5 \mathrm{~min}$ at $5000 \times g$ and the supernatant of each sample was aliquoted and stored at $-80^{\circ} \mathrm{C}$.

2.3.3.2. Analysis of norepinephrine levels. A specific kit quantified the norepinephrine levels (Catalog. No: U0907Ge; Wuhan EIab Science Co. Ltd., China) through the enzyme-linked immunosorbent assay (ELISA), according to the manufacturer's recommendations. The assay sensitivity was less than $7.5 \mathrm{pg} / \mathrm{mL}$; coefficient of variation of intra-assay and inter-assay (CV) was $<4.3 \%$ and $7.5 \%$, respectively. The assay was performed in triplicate.
2.3.3.3. Analysis of corticosterone, ACTH and BDNF concentrations.. The levels of corticosterone, ACTH and BDNF in the tissue samples were measured by the Milliplex Multi-Analyte Profiling method through the Luminex $\mathrm{xMAP}^{\mathrm{TM}}$ technology. To perform these immunoassays, Milliplex $^{\mathrm{TM}}$ specific kits (ACTH, corticosterone, Catalog. No: RSHMAG69K; BDNF, Catalog. No: RPTMAG-86K; Millipore, Billerica, MA, USA) were used according to the manufacturer's recommendations. The assay sensitivities were $2914 \mathrm{pg} / \mathrm{mL}$ for corticosterone, $0.9 \mathrm{pg} / \mathrm{mL}$ for ACTH and $0.38 \mathrm{pg} / \mathrm{mL}$ for BDNF; intra- and inter-assays CVs were $<10 \%$ for corticosterone and ACTH, $1.7 \%$ and $12.2 \%$ for BDNF, respectively. All assays were run in triplicate. 
2.3.3.4. Normalization of hormonal levels. In the tissue homogenates, total protein concentration was measured using the method of Lowry et al. (1951) and the data were used to normalize the stress hormones levels. The hormonal levels were expressed as pg (of hormone)/ $\mu \mathrm{g}$ (of total protein) in $1 \mathrm{~mL}$ of tissue homogenate.

\subsection{Oral carcinogenesis induction}

Three weeks after the biopsy, all animals were anesthetized again to check oral mucosal healing. All animals exhibited the dorsum surface of the tongue healed and were included in the next phase of study (chemically induced carcinogenesis). For tumor induction, the animals were treated with $50 \mathrm{ppm}$ of 4-nitroquinoline-1-oxide (4NQO) (SigmaAldrich, St. Louis, MO, USA) diluted in drinking water. All animals had free access to water with the carcinogen solution, which was replenished twice a week. The animals were euthanized by decapitation after a 20 weeks period of carcinogenic induction (Kanojia and Vaidya, 2006). In the third phase of study, the tongues with carcinogen-induced lesions were extracted to perform histopathological analysis, measurements of the stress hormones levels in the microenvironment, and gene expression analysis by RT-PCR assay.

\subsection{Histopathological analysis}

To perform histopathological analysis, the tongues were longitudinally sectioned and fixed in $10 \%$ buffered formaldehyde for $48 \mathrm{~h}$. Then, these tissues were paraffin-embedded, sectioned at $4 \mu \mathrm{m}$ and stained with Hematoxylin and Eosin (H\&E) (Merck, Darmstadt, Germany). The tongue lesions derived from 4NQO treatment were classified in oral leukoplakia and oral squamous cell carcinoma (OSCC). Oral leukoplakia is considered a precursor lesion of OSCC (Warnakulasuriya et al., 2007). For the diagnosis of oral leukoplakia, we considered the following microscopic features: atrophy of the epithelium, hyperplasia with or without hyperkeratosis and epithelial dysplasia (van der Waal et al., 1997). The degree of epithelial dysplasia was classified in mild, moderate or severe (Barnes et al., 2005). According to Bryne's criteria (Bryne, 1998), two oral pathologists (A.M.P.S. and G.I.M.) determined the histological grade of malignancy of the OSCCs. In this analysis, the degree of keratinization, nuclear pleomorphism, lymphoplasmocytic infiltrate and the pattern of invasion were assessed in the invasive front of tumors (Bryne, 1998).

\subsection{Tumor thickness}

To measure tumor thickness, microscopic images of OSCC slides were captured on a microscope equipped with a digital camera (DM4000B Leica, Wetzlar, Germany). The measurement was performed from the deepest point of tumor invasion to the surface of the ulcer or epithelium and was obtained (in $\mu \mathrm{m}$ ) using the Qwin Plus software (Leica Microsystem Imaging Solutions Ltd., Cambridge, UK).

\subsection{Tumor volume and weight loss}

A digital caliper obtained (in $\mathrm{mm}$ ) the three-dimensional measurements of the tumor (depth, width and length). Tumor volume (in $\mathrm{mm}^{3}$ ) was calculated using the following formula: volume = depth $\times$ width $\times$ length. Body weight of each animal was recorded weekly. These measurements were used to calculate the weight loss during the period of carcinogenesis.

\subsection{Stress hormones levels in the microenvironment post-carcinogenic induction}

To assess whether chemically induced carcinogenesis promoted changes in the stress hormones concentrations in the tongue microenvironment, post-carcinogen levels of norepinephrine, corticosterone,
ACTH and BDNF were analyzed in oral leukoplakia and tumor tissues. To measure the stress hormones levels, the same immunoassay techniques described above (ELISA and Milliplex Multi-Analyte Profiling) were used.

\subsection{Expression of tumor progression-related genes by RT-PCR}

In order to assess the associations between mRNA expression levels of five genes involved in cancer progression (Bernabé et al., 2011; Lutgendorf et al., 2003; Lutgendorf et al., 2008a; Lutgendorf et al., 2008b; Nilsson et al., 2007; Sood et al., 2006; Thaker et al., 2006; Yang et al., 2006) and the stress hormones levels in the microenvironment, the tumor samples were analyzed by RT-PCR technique. Total RNA was extracted using the Trizol reagent. Then, RNA samples were suspended in $20 \mu \mathrm{L}$ of RNase-free ultrapure water for synthesis of complementary DNA (cDNA). RNA quantity and quality were verified by spectrophotometry and cDNA was synthesized with a specific kit (High Capacity RNA to cDNA kit; Invitrogen Life Technologies) using $2 \mu \mathrm{g}$ of total RNA, according to the manufacturer's recommendations. $\mathrm{TaqMan}^{\mathrm{TM}}$ RT-PCR assay measured the mRNA levels by the StepOne Real-Time PCR system (Applied Biosystems, Foster City, CA, USA). The primers for IL-6 (Rn00569848_m1), MMP-2 (Rn01538170_m1), MMP-9 (Rn00579162_m1), VEGF (Rn01511601_m1) and CDKN2ap16 (Rn00580664_m1) were analyzed. ß-actin (Rn00562253_m1) gene was used as endogenous control. The reactions were performed with a $20 \mu \mathrm{L}$ final volume. Thermal cycling conditions followed the manufacturer's recommendations. The expression levels of each gene in each sample were normalized to $ß$-actin mRNA levels. mRNA Relative Quantity (RQ) for each target gene was calculated using comparative $C_{T}$ method.

\subsection{Statistical analysis}

Statistical Analysis System 9.2 (SAS Institute Inc., Cary, NC, USA), GraphPad Prism 6.01 (GraphPad Software Inc., San Diego, CA, USA) and RStudio using R version 3.2.0 (Integrated Development for RStudio Inc., Boston, MA, USA) softwares were used to perform all statistical tests. Simple linear regression test and penalized regression analysis, a multiple regression model, were used to predict OSCC occurrence. Precarcinogen stress hormones data were entered into the multiple analysis as independent variables. Clinicopathological and gene expression data were submitted into this model as response variables using the $R$ function 'glmnet'. Penalized regression reduced the number of predictors by taking into account their correlation coefficients. The LASSO penalty was used in this analysis. Student's $t$-test was used to determine the differences between pre- and post-carcinogen hormones levels in the microenvironment. Pre- and post-carcinogen stress hormones data were submitted to correlation analysis. This test was also used to evaluate associations among post-carcinogen hormones data and response variables. The level of statistical significance was set at a $p$ value less than 0.05 for all statistical tests.

\section{Results}

3.1. Pre-carcinogen concentrations of norepinephrine and corticosterone in
the normal tongue microenvironment predict cancer occurrence

After chemically induced carcinogenesis, 33 rats $(68.75 \%)$ had OSCC and 15 rats (31.25\%) developed oral leukoplakia, a precursor lesion of OSCC (Fig. 1E-H). According to Bryne's criteria (Bryne, 1998), all OSCCs were classified as mildly aggressive tumors. Microscopic analysis showed that $80 \%$ of leukoplakias were diagnosed with moderate and severe epithelial dysplasia.

Simple linear regression analysis was performed to investigate whether individual pre-carcinogen stress hormones levels in the normal microenvironment are predictive for OSCC occurrence. Increased pre- 
(A)

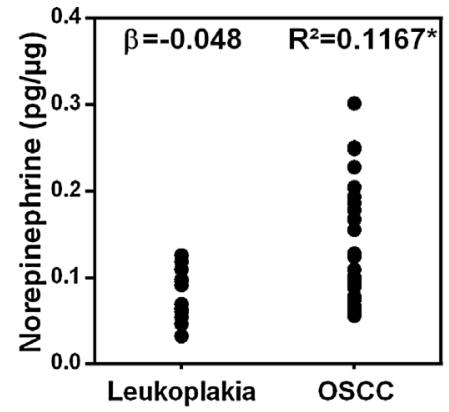

(B)

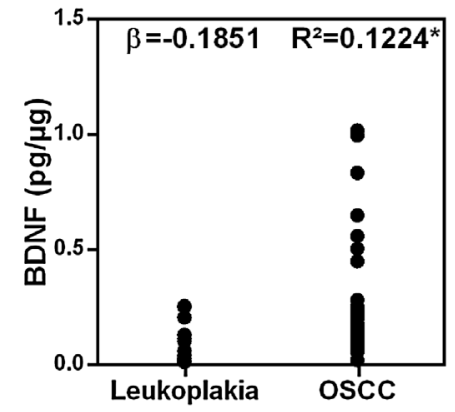

(C)

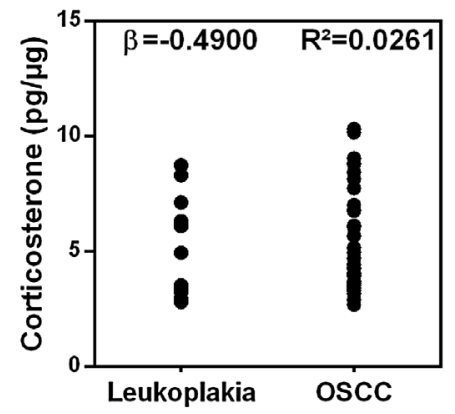

(D)

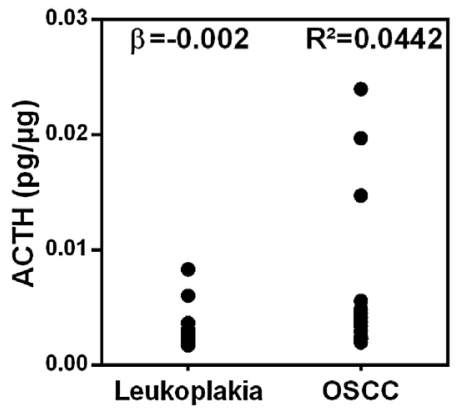

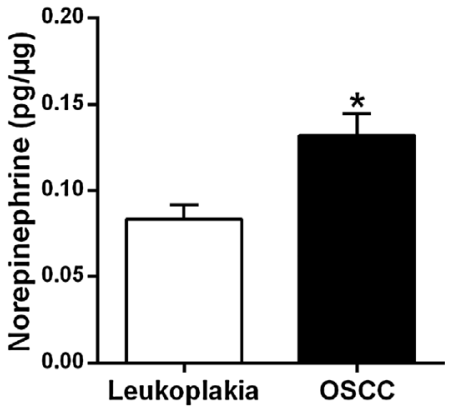

Fig. 2. Simple linear regression analysis among the pre-carcinogen levels of norepinephrine (A, $n=44)$, BDNF (B, $n=47$ ), corticosterone (C, $\mathrm{n}=43)$ and ACTH (D, n = 41) vs occurrence of oral leukoplakia and OSCC. Pre-carcinogen levels of norepinephrine and BDNF in the tongue microenvironment predicted oral cancer $\left({ }^{*} \mathrm{p}<0.05\right)$. Student's test- $t$ between the pre-carcinogen stress hormones levels; bar graphs with labeled error bars $\left( \pm\right.$ SEM) $\left({ }^{*} \mathrm{p}<0.05\right)$.
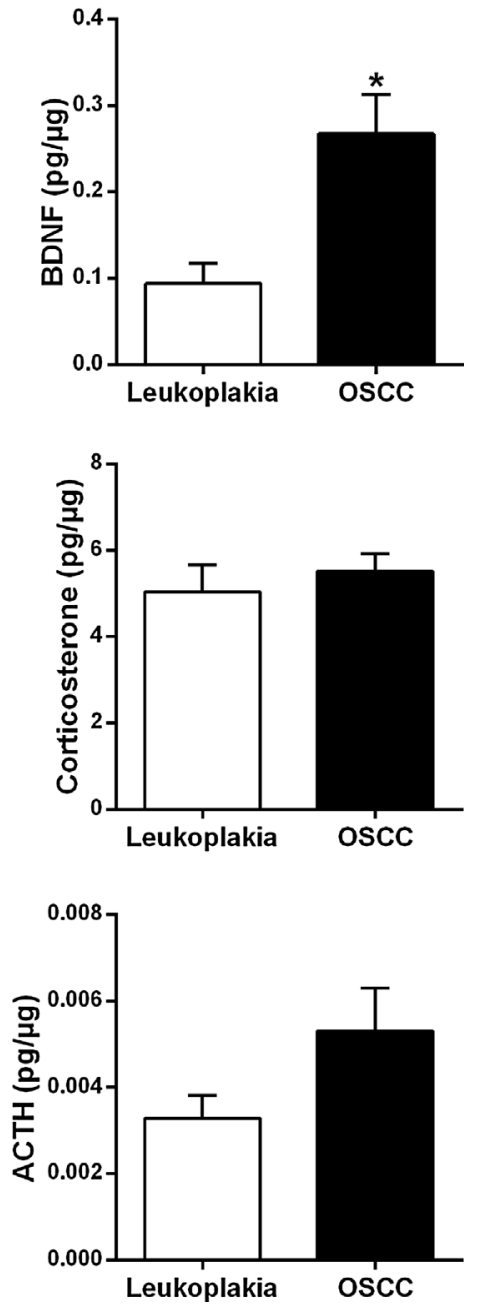

Table 1

Pre-carcinogen stress-related hormones in the tongue microenvironment and OSCC occurrence risk.

\begin{tabular}{llll}
\hline & Estimate & z Value & p Value \\
\hline Norepinephrine & 35.40 & 2.420 & $0.025^{*}$ \\
Corticosterone & -0.63 & -2.056 & $0.039^{*}$ \\
ACTH & 195.62 & 0.692 & 0.489 \\
BDNF & 10.53 & 1.775 & 0.068 \\
\hline
\end{tabular}

* Values considered statistically significant at $\mathrm{p}<0.05$ (penalized regression analysis).

carcinogen concentrations of norepinephrine (pre-carcinogen normal mucosa of OSCC, $0.1319 \pm 0.0127 \mathrm{pg} / \mu \mathrm{g}$; pre-carcinogen normal mucosa of oral leukoplakia, $0.0834 \pm 0.0085 \mathrm{pg} / \mu \mathrm{g} ; \mathrm{p}=0.023$ ) and BDNF (pre-carcinogen normal mucosa of OSCC, $0.2670 \pm 0.0458 \mathrm{pg} /$

$\mu g$; pre-carcinogen normal mucosa of oral leukoplakia, $0.0818 \pm 0.0212 \mathrm{pg} / \mu \mathrm{g} ; \mathrm{p}=0.021$ ) in the tongue microenvironment were positively correlated to OSCC occurrence (Fig. 2A and B). Nevertheless, pre-carcinogen tissue levels of corticosterone (pre-carcinogen normal mucosa of OSCC, $5.518 \pm 0.7416 \mathrm{pg} / \mu \mathrm{g}$; pre-carcinogen normal mucosa of oral leukoplakia, $5.029 \pm 0.6357 \mathrm{pg} / \mu \mathrm{g}$; $\mathrm{p}=0.520$ ) and ACTH (pre-carcinogen normal mucosa of OSCC, $0.0053 \pm 0.0009 \mathrm{pg} / \mu \mathrm{g}$; pre-carcinogen normal mucosa of oral leukoplakia, $0.0032 \pm 0.0005 \mathrm{pg} / \mu \mathrm{g} ; \mathrm{p}=0.186)$ were not associated with oral cancer occurrence (Fig. 2C and D). Penalized regression was performed to identify the most relevant stress hormones to predict OSCC risk (Table 1). In this analysis, higher pre-carcinogen norepinephrine levels were positively correlated with cancer occurrence $(\mathrm{p}=0.025)$. Increased pre-carcinogen BDNF concentrations were correlated with a positive trend for cancer occurrence risk $(p=0.068)$. When the predictive effects of the four molecules were assayed together 
Table 2

Predictive value of the pre-carcinogen stress hormones for clinicopathological variables and molecular features.

\begin{tabular}{|c|c|c|c|c|c|c|c|c|c|c|c|c|}
\hline \multirow[t]{2}{*}{ Variables $^{\text {k** }}$} & \multicolumn{3}{|c|}{ Norepinephrine } & \multicolumn{3}{|c|}{ Corticosterone } & \multicolumn{3}{|l|}{ АСТН } & \multicolumn{3}{|l|}{ BDNF } \\
\hline & Estimate & t Value & $\mathrm{p}$ Value & Estimate & t Value & $\mathrm{p}$ Value & Estimate & t Value & $\mathrm{p}$ Value & Estimate & t Value & $\mathrm{p}$ Value \\
\hline \multicolumn{13}{|l|}{ Clinicopathological } \\
\hline Tumor volume & 1022.72 & 0.774 & 0.446 & -21.35 & -0.543 & 0.592 & 49587.91 & 1.415 & 0.169 & -8.49 & -0.017 & 0.986 \\
\hline Tumor thickness & 7952.0 & 1.185 & 0.246 & -180.47 & -0.909 & 0.366 & 27559.27 & 1.559 & 0.131 & -96.85 & -0.039 & 0.969 \\
\hline Weight loss & -107.80 & -0.647 & 0.521 & -4.44 & -0.997 & 0.325 & 1012.57 & 0.250 & 0.804 & 44.21 & 0.723 & 0.474 \\
\hline Keratinization degree & 0.91 & 0.552 & 0.585 & 0.05 & 1.211 & 0.236 & -42.77 & -0.961 & 0.345 & 0.36 & 0.594 & 0.558 \\
\hline Nuclear pleomorphism & -8.90 & -0.364 & 0.716 & -1.16 & -1.209 & 0.227 & 288.29 & 0.567 & 0.571 & -10.08 & -1.107 & 0.268 \\
\hline Pattern of invasion & -1.95 & -0.487 & 0.630 & -0.26 & -1.890 & 0.069 & 105.30 & 1.186 & 0.245 & 0.82 & 0.802 & 0.429 \\
\hline Lymphoplasmocytic infiltrate & -16.47 & -1.763 & 0.077 & 0.49 & 1.826 & 0.067 & -348.29 & -1.496 & 0.134 & -0.42 & -0.184 & 0.853 \\
\hline \multicolumn{13}{|l|}{ mRNA expression } \\
\hline VEGF & -75.96 & -1.450 & 0.168 & 2.05 & 1.218 & 0.242 & -715.31 & -0.390 & 0.702 & -0.44 & -0.030 & 0.976 \\
\hline MMP-2 & -31.85 & -1.706 & 0.109 & 0.73 & 1.231 & 0.237 & -76.20 & -0.117 & 0.909 & 2.02 & 0.385 & 0.705 \\
\hline MMP-9 & -48.04 & -0.305 & 0.765 & 2.43 & 0.481 & 0.638 & -1567.41 & -0.284 & 0.780 & -7.24 & -0.163 & 0.873 \\
\hline IL-6 & -37.63 & -0.385 & 0.706 & -0.71 & -0.221 & 0.828 & -359.66 & -0.102 & 0.920 & 3.44 & 0.145 & 0.887 \\
\hline CDKN2a-p16 & -12.74 & -2.420 & $0.028^{*}$ & 0.27 & 1.608 & 0.128 & 142.86 & 0.775 & 0.450 & 2.63 & 1.775 & 0.096 \\
\hline
\end{tabular}

* Value considered statistically significant at $\mathrm{p}<0.05$ (penalized regression analysis).

** Only tumor data are included in this table.

by the penalized regression, higher pre-carcinogen corticosterone concentrations were negatively correlated with OSCC occurrence $(\mathrm{p}=0.039)$.

\subsection{Increased pre-carcinogen norepinephrine levels are predictive for lower expression of pCDKN2a-p16 in the tumor microenvironment}

Penalized regression showed the predictive value of the pre-carcinogen stress hormones levels in the normal tongue microenvironment for clinicopathological variables and tumor progression-related genes in OSCCs (Table 2). None of the pre-carcinogen hormonal levels was correlated with clinicopathological variable such as tumor volume and thickness or body weight loss in cancer rats $(\mathrm{p}>0.05)$. Tumor histopathological features, such as the degree of keratinization, nuclear pleomorphism, lymphoplasmocytic infiltrate and the pattern of invasion were not correlated with the pre-carcinogen stress hormones levels ( $p>0.05$ ). In rats with oral leukoplakia, none of the hormones was correlated with the degree of epithelial dysplasia $(p>0.05)$. Increased pre-carcinogen norepinephrine concentrations were predictive for lower expression of CDKN2a-p16 in the tumor microenvironment ( $p=0.028$ ). However, the expressions of VEGF, MMP-2, MMP-9 and IL-6 in OSCCs were not correlated with the pre-carcinogen hormones concentrations $(\mathrm{p}>0.05)$.

\subsection{Chemically induced carcinogenesis promotes hormonal changes in the target microenvironment}

The modulation of the hormonal levels induced by 4NQO treatment was evaluated in the tongue microenvironment. For this, student's $t$-test was performed to identify differences between pre- and post-carcinogen hormonal concentrations. Post-carcinogen corticosterone levels in OSCCs $(32.752 \pm 7.558 \mathrm{pg} / \mu \mathrm{g})$ and oral leukoplakia $(19.259 \pm 4.246 \mathrm{pg} / \mu \mathrm{g})$ tissues were higher than hormone concentrations in the tongue microenvironment before carcinogenic induction (OSCC, $5.518 \pm 0.401 \mathrm{pg} / \mu \mathrm{g} ; \quad$ oral leukoplakia, $5.028 \pm 0.635 \mathrm{pg} / \mu \mathrm{g})(\mathrm{p}<0.01)$ (Fig. 3A). Likewise, higher BDNF concentrations were found in the leukoplastic lesions $(0.240 \pm 0.037 \mathrm{pg} / \mu \mathrm{g})$ when compared to pre-carcinogen tissue $(0.093 \pm 0.023 \mathrm{pg} / \mu \mathrm{g})(\mathrm{p}=0.008)$. There were no differences between the BDNF concentrations of the normal tissue $(0.266 \pm 0.045 \mathrm{pg} / \mu \mathrm{g})$ and OSCC $(0.238 \pm 0.019 \mathrm{pg} / \mu \mathrm{g})$ $(\mathrm{p}=0.653$ ) (Fig. 3B). No differences were found between pre- and post-carcinogen concentrations of norepinephrine (Fig. 3C) and ACTH (Fig. 3D) for leukoplastic lesions and OSCCs ( $p>0.05$ ). There were no differences between the post-carcinogen hormonal levels of the oral leukoplakia tissue and OSCC (p > 0.05) (Fig. 3). Even with the postcarcinogen ACTH levels from oral leukoplakia and OSCC analyzed together, the pre-carcinogen hormone levels in the tongue microenvironment were higher $(\mathrm{p}=0.014$; Fig. S1C in the online version at DOI: http://dx.doi.org/10.1016/j.psyneuen.2017.11.001), suggesting that the ACTH tissue levels decrease after 4NQO treatment. Precarcinogen stress hormones tissue levels were positively correlated to each other ( $\mathrm{p}<0.001$; Fig. S2A, C, E, G, I and $\mathrm{K}$ in the online version at DOI: http://dx.doi.org/10.1016/j.psyneuen.2017.11.001). However, this correlation was lost after carcinogenic induction. Only the postcarcinogen ACTH levels were positively correlated with the postcarcinogen levels of norepinephrine $(\mathrm{p}<0.001$; Fig. S2D in the online version at DOI: http://dx.doi.org/10.1016/j.psyneuen.2017.11. 001), corticosterone ( $\mathrm{p}=0.035$; Fig. S2H in the online version at DOI: http://dx.doi.org/10.1016/j.psyneuen.2017.11.001) and BDNF ( $\mathrm{p}<0.001$; Fig. S2L in the online version at DOI: http://dx.doi.org/ 10.1016/j.psyneuen.2017.11.001). These results indicate an imbalance in stress hormones levels into microenvironment during carcinogenesis induction.

3.4. Stress hormones levels in the tumor microenvironment are associated with cancer growth and immune response

When clinicopathological variables from OSCCs were correlated with post-carcinogen stress hormones concentrations, higher norepinephrine tissue levels were associated to increased tumor volume $(\mathrm{p}<0.001)$. Likewise, an increase of tumor thickness was also correlated with higher norepinephrine levels in the tumor microenvironment ( $p=0.003$ ). Body weight loss of the animals with OSCC during the period of carcinogenesis was not associated to the post-carcinogen stress hormones levels ( $p>0.05$ ). In addition, histopathological features of malignancy such as the degree of keratinization or nuclear pleomorphism and the pattern of invasion were not associated with the hormones concentrations in the tumor microenvironment $(\mathrm{p}>0.05)$. Increased tissue levels of norepinephrine $(p=0.015)$, ACTH ( $p=0.015)$ and BDNF ( $=0.019)$ were associated with a lesser intensity of the lymphoplasmocytic infiltrate. In rats with oral leukoplakia, the post-carcinogen stress hormones concentrations were not associated with the degree of epithelial dysplasia ( $p>0.05$ ). The associations between post-carcinogen stress hormones levels and clinicopathological variables are shown in Table 3. The expressions of VEGF, MMP-2, MMP-9 and CDKN2a-p16 in OSCCs were not associated with the post-carcinogen hormones levels ( $p>0.05$ ). However, IL-6 
(A)

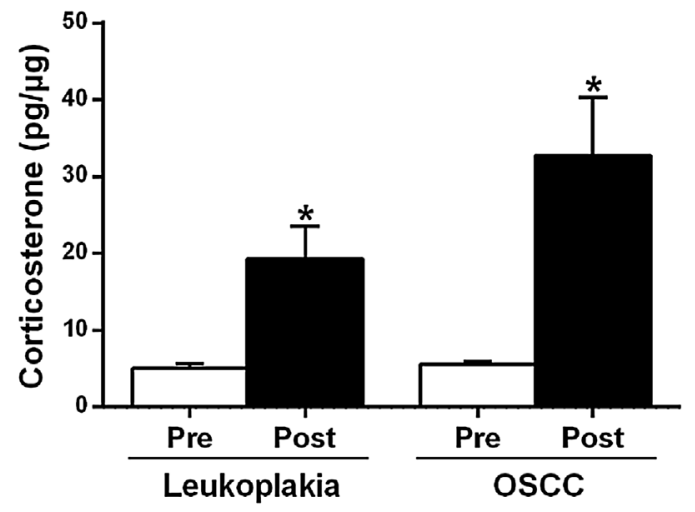

(C)

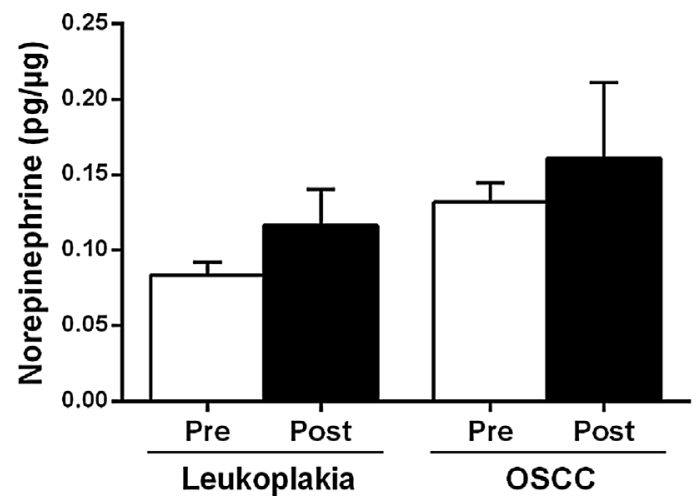

(B)

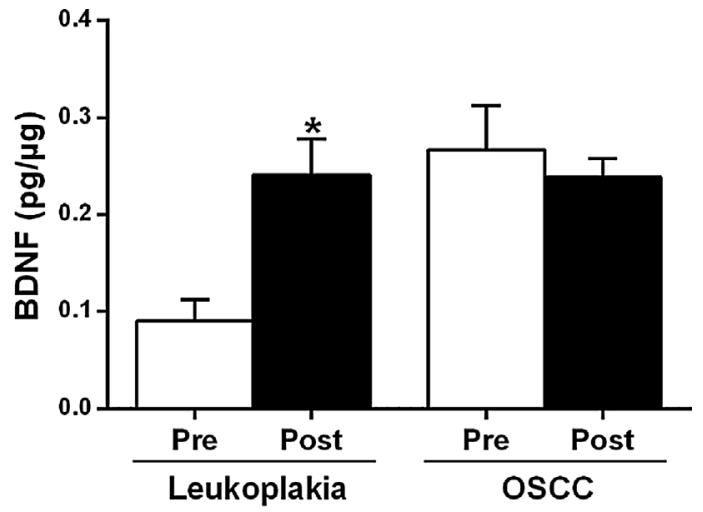

(D)

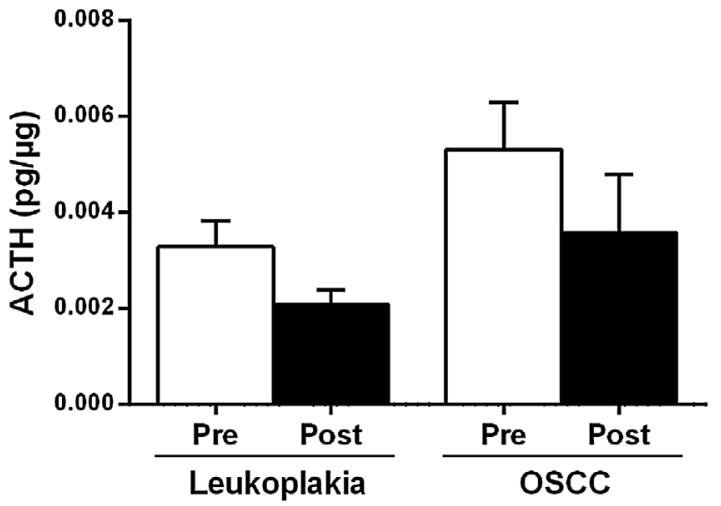

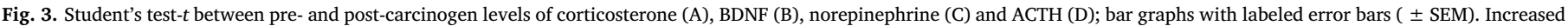
corticosterone levels were found in the tumor and leukoplastic lesions (*p $<0.05$ ) while higher BDNF levels were found only in the leukoplastic lesions (* $\mathrm{p}<0.05)$.

overexpression was associated to increased corticosterone levels in the tumor microenvironment $(\mathrm{p}<0.001)$

\section{Discussion}

For a long time, it has been speculated that stress hormones could influence cancer progression and onset. Although studies show that stress increases the stress hormones concentrations in peripheral tissues affecting tumor progression (Antoni et al., 2006; Reiche et al., 2004; Thaker et al., 2006), its influence on cancer occurrence is poorly understood. In this context, what is more obscure is the role of stress hormones in cancer induction. Although recent findings demonstrate that stress hormones can induce the malignant phenotype in non-cancerous cells (Feng et al., 2012; Flint et al., 2013; Hara et al., 2011), there are no studies that evaluated the predictive value of the stress hormones levels in the normal microenvironment for cancer onset and progression. In this study, we used a new method based on a classic model of chemically induced carcinogenesis to assess the predictive value of the stress hormones levels in the peripheral tissue for oral cancer occurrence. Our results showed that increased pre-carcinogen concentrations of norepinephrine and BDFN and reduced basal corticosterone levels in the normal microenvironment were predictive for OSCC occurrence. To measure these levels, we used tongue tissue of the same target region, which would later undergo the carcinogen action

Table 3

Post-carcinogen stress hormones vs clinicopathological variables and molecular features.

\begin{tabular}{|c|c|c|c|c|c|c|c|c|c|c|c|c|}
\hline \multirow[t]{2}{*}{ Variables $^{* * *}$} & \multicolumn{3}{|c|}{ Norepinephrine } & \multicolumn{3}{|c|}{ Corticosterone } & \multicolumn{3}{|l|}{ ACTH } & \multicolumn{3}{|l|}{ BDNF } \\
\hline & $\mathrm{R}$ & $\mathrm{R}^{2}$ & $\mathrm{p}$ Value & $\mathrm{R}$ & $\mathrm{R}^{2}$ & $\mathrm{p}$ Value & $\mathrm{R}$ & $\mathrm{R}^{2}$ & p Value & $\mathrm{R}$ & $\mathrm{R}^{2}$ & $\mathrm{p}$ Value \\
\hline \multicolumn{13}{|l|}{ Clinicopathological } \\
\hline Tumor volume & 0.852 & 0.7259 & $<0.001^{*}$ & -0.060 & 0.0036 & 0.793 & -0.064 & 0.0040 & 0.780 & -0.096 & 0.0092 & 0.686 \\
\hline Tumor thickness & 0.726 & 0.5270 & $0.003^{*}$ & -0.039 & 0.0015 & 0.866 & -0.063 & 0.0039 & 0.784 & -0.080 & 0.0064 & 0.736 \\
\hline Weight loss & -0.073 & 0.0053 & 0.742 & -0.294 & 0.0864 & 0.114 & 0.064 & 0.0040 & 0.534 & 0.092 & 0.0084 & 0.434 \\
\hline Keratinization degree & -0.056 & 0,0031 & 0.807 & 0.144 & 0,0207 & 0.544 & 0.049 & 0.0024 & 0.834 & 0.048 & 0.0023 & 0.842 \\
\hline Nuclear pleomorphism & -0.060 & 0.0036 & 0.793 & 0.195 & 0.0380 & 0.408 & -0.115 & 0.0132 & 0.627 & -0.110 & 0.0121 & 0.651 \\
\hline Pattern of invasion & -0.092 & 0.0084 & 0.690 & -0.030 & 0.0009 & 0.900 & -0.117 & 0.0136 & 0.621 & -0.121 & 0.0146 & 0.621 \\
\hline Lymphoplasmocytic infiltrate & -0.437 & 0.1909 & $0.015^{*}$ & -0.313 & 0.0979 & 0.178 & -0.531 & 0.2819 & $0.015^{*}$ & -0.529 & 0.2798 & $0.019^{*}$ \\
\hline \multicolumn{13}{|l|}{ mRNA expression } \\
\hline VEGF & -0.220 & 0,0484 & 0.336 & 0.063 & 0.0039 & 0.785 & -0.042 & 0.0017 & 0.855 & -0.052 & 0.0027 & 0.824 \\
\hline MMP-2 & -0.201 & 0.0404 & 0.381 & 0.270 & 0.0729 & 0.236 & 0.020 & 0.0004 & 0.930 & 0.022 & 0.0004 & 0.923 \\
\hline MMP-9 & -0.063 & 0.0039 & 0.783 & 0.199 & 0.0396 & 0.386 & -0.014 & $<0.0001$ & 0.951 & 0.058 & 0.0033 & 0.808 \\
\hline IL-6 & -0.033 & 0.0010 & 0.887 & 0.817 & 0.6674 & $<0.001^{*}$ & -0.001 & $<0.0001$ & 0.994 & -0.037 & 0.0013 & 0.877 \\
\hline CDKN2a-p16 & -0.094 & 0.0088 & 0.682 & 0.009 & $<0.0001$ & 0.968 & 0.105 & 0.0110 & 0.647 & 0.090 & 0.0081 & 0.703 \\
\hline
\end{tabular}

* Values considered statistically significant at $\mathrm{p}<0.05$ (correlation analysis).

** Only tumor data are included in this table. 
for OSCC induction. Stress hormones levels in peripheral tissues are a sensitive tool to analyze hormonal changes triggered by chronic stress and can be more stable than plasma concentrations (Thaker et al., 2006). In addition, the tissue levels are more representative for assessing the endocrine changes in a target microenvironment, as well their role as a cofactor of chemical substances in cancer induction.

In our findings, animals with increased pre-carcinogen norepinephrine concentrations in the tongue microenvironment had 35 times higher chance of developing tongue carcinomas (Table 1). Norepinephrine can induce significant changes in molecular pathways of the carcinogenesis process (Hara et al., 2011; Landen et al., 2007; Muthalif et al., 1998). A study demonstrated that norepinephrine acts via both Gs-protein kinase A (PKA) and $\beta$-arrestin-mediated signaling pathway inducing DNA damage and suppressing p53 levels through the AKT-mediated activation of MDM2 (Hara et al., 2011). These molecular events increase the cellular tumorigenicity of non-cancerous cells. In 3T3 mouse fibroblasts, per example, chronic exposure to increased norepinephrine levels causes an increase in DNA damage (Flint et al., 2013). ß-adrenergic signaling can also activate oncogenic mechanisms via transcription factor STAT 3 (Landen et al., 2007) and RAS signaling pathway (Muthalif et al., 1998). According to Fitzgerald (2009), higher norepinephrine concentrations can stimulate the adrenergic receptors increasing the chances of developing cancer. Although peripheral innervation of the tongue has not been evaluated in this study, it seems to be very likely that the sympathetic nerve fibers of the microenvironment be responsible for the production of norepinephrine. Anyway, the results of this research strongly indicate that (not stress-induced) increased norepinephrine concentrations in the normal microenvironment can be an important cofactor, in conjunction with carcinogenic substances, for cancer development. Interestingly, higher pre-carcinogen norepinephrine levels were also predictive for lower expression of pCDKN2a-p16 in the tumor microenvironment. CDKN2a-p16 is an important tumor-suppressor gene and its mutation is a frequent event in the tongue OSCC (Lim et al., 2014). This gene encodes the p16 protein, which inhibits the activity of CDK-4 and CDK-6 stopping G1-S phase transition of the cell cycle (Liggett and Sidransky, 1998; Lim et al., 2014). In human tumors, CDKN2a-p16 inactivation is associated with loss of p16 protein expression (Liggett and Sidransky, 1998). Further studies are necessary to elucidate the noradrenergic signaling pathways that could inactivate this tumor-suppressor gene.

This study showed that higher pre-carcinogen corticosterone levels in the tongue microenvironment were negatively correlated with OSCC occurrence. In our initial hypothesis, the predictive value of the corticosterone concentrations for chemical carcinogenesis should be similar to norepinephrine's. Recently, Pyter and Prendergast (2013) found that increased plasma corticosterone levels prior to carcinogen treatment predicted mammary cancer onset, but the authors did not evaluate the hormone tissue levels in the microenvironment. However, some evidences can support the negative predictive effect of glucocorticoid for carcinogenesis. In female rats, per example, dietary administration of corticosterone promoted a dose-dependent reduction in the occurrence, multiplicity and size of mammary carcinomas (Zhu et al., 2003). In a more recent study, the glucocorticoid-mediated COX-2 inhibition promoted a reduction of the 11ß-hydroxysteroid dehydrogenase type II in lung cancer cells (Chang et al., 2015). In vivo, this reduction decreased tumor growth and invasion in association with higher tissue glucocorticoids concentrations (Chang et al., 2015). In our study, reduced pre-carcinogen corticosterone levels in the tongue microenvironment were predictive for OSCC occurrence. Although these hormone concentrations can be produced by the HPA axis in the adrenal cortex, there is evidence that glucocorticoids may also be produced by the intracellular HPA axis of the microenvironment cells (Anna et al., 2007). Pre-carcinogen ACTH concentrations in tongue microenvironment, differently of norepinephrine and corticosterone, were not predictive for oral cancer occurrence.

Similar to norepinephrine concentrations, increased pre-carcinogen
BDNF levels in the tongue microenvironment were positively correlated with OSCC occurrence in the simple regression analysis. In response to stress, the BDFN levels increase (Saruta et al., 2010; Tsukinoki and Saruta, 2012) and can activate the TrkB receptors of PC12 cells in the rodents' adrenal medulla, which can release norepinephrine and epinephrine into the bloodstream (Tsukinoki and Saruta, 2012). BDNF is overexpressed in head and neck carcinomas and may induce cellular migration and tumor invasion via TrkB activation (Kupferman et al., 2010). Oncogenic mechanisms such as the upregulation of PI3K-AKTcascade (Chao and Lee, 2004) and MAPK p42/44 phosphorylation (Smit et al., 2009) can be activated by BDNF. In addition, the TrkB overexpression results in an altered expression of E-cadherin (with downregulation, in epithelium) and Twist (with upregulation, in mesenchyme) in the microenvironment (Kupferman et al., 2010). Interestingly, Twist transcriptional activity induces severe alterations in epithelial cells (Smit et al., 2009). The data of the present study suggest a specific role of this neurotrophin for chemical carcinogenesis.

For a better understanding of the modulation of stress hormones levels in the microenvironment after chemically induced oral carcinogenesis, the pre-carcinogen hormonal concentrations were compared to post-carcinogen levels. The results showed that the $4 \mathrm{NQO}$ treatment increased the corticosterone levels in the microenvironment of the oral leukoplakia tissues and OSCCs. The BDNF levels were also higher in the oral leukoplakia tissues than in the normal oral mucosa before carcinogenesis. Chemically induced oral carcinogenesis itself can be associated with increased stress levels derived from tongue pain (Ye et al., 2011) or a difficulty eating/swallowing. These levels could result in increases in local corticosterone concentrations. In addition to stress effects, cancer cells could have a higher density of glucocorticoid receptors (Block et al., 2017) than non-cancerous cells creating a stronger retention of corticosterone locally. Other possible explanation for an increase in local corticosterone levels is that chronic exposure to chemical carcinogen could lead to a deregulated production of this mediator by the microenvironment cells during tumor induction. The substantial increase in corticosterone concentrations, per example, could also be related to an cellular endocrine activity derived from stressorlike effects of carcinogen. Anna et al. (2007) proposed that UV radiation leads to a persistent activation of the intracellular HPA axis in melanoma cells resulting in the production of glucocorticoids. Future studies are mandatory to investigate the potential activity of an intracellular HPA axis in tumor microenvironment cells in response to 4NQO exposure. When the ACTH concentrations in oral leukoplakia tissues and OSCCs were analyzed together, the post-carcinogen hormone levels were lower than the pre-carcinogen's; an opposite result to that obtained with corticosterone. We can suppose that increased local corticosterone concentrations could be inhibiting the production of ACTH by the tumor microenvironment cells (negative feedback effect). In another investigation, Al-Wadei et al. (2012) showed that pancreatic cancer cells produced norepinephrine upon exposure to nicotine. Here, although carcinogenic induction has increased the norepinephrine levels in the microenvironment this result did not reach statistical significance.

Higher norepinephrine levels in the OSCC microenvironment were associated with a greater tumor volume and thickness. Recently, a preclinical study with nude mice showed a positive correlation between chronic stress and increased plasma levels of catecholamines and glucocorticoid, greater tumor size and more invasive growth of human oral cancer cells (Xie et al., 2015). Another study demonstrated that higher norepinephrine concentrations derived from chronic stress induced ovarian carcinoma growth and angiogenesis in an orthotopic mouse model through the activation of PKA and overexpression of VEGF, MMP-2 and MMP-9 (Thaker et al., 2006). Similarly, norepinephrine treatment increased the levels of invasiveness, VEGF, MMP-2 and MMP9 in culture supernatants of nasopharyngeal carcinoma cells (Yang et al., 2006) and proliferation of OSCC cells (Bernabé et al., 2011) in a dose-dependent response. In this study, increased corticosterone levels 
in the tumor microenvironment were associated to enhanced IL-6 mRNA levels. Previously, we showed that cortisol stress levels tended to increase IL-6 expression in a human OSCC cell line (Bernabé et al., 2011). Stress hormones can inhibit the lymphocytes functions and cellular immune responses against some tumors (Reiche et al., 2004). In our research, post-carcinogen higher levels of norepinephrine, ACTH and BDNF were associated with a lesser intensity of the lymphoplasmocytic infiltrate, suggesting a probable immunosuppressive effect of these mediators in the tumor microenvironment. ACTH has been considered an important immune regulator for chemotaxis and phagocytosis (Ottaviani et al., 1999), whereas BDNF can decrease the levels of NK cells (Yu et al., 2016).

In humans, the conduction of prospective studies that allow to evaluate the role of stress hormones on cancer development is not simple. Although it is an excellent resource for studying the impact of stress hormones on carcinogenesis process, the collection of biological samples from human peripheral tissues before cancer onset requires a large population sample and its follow-up until cancer occurrence. In this study, we have succeeded in reproducing this methodological perspective in animals in order to study the stress hormones levels in the normal tissue microenvironment, which would be induced to cancer some time later. This preclinical model also provides perspectives of its use for the investigation of physiological and genetic changes in the microenvironment and their effects on carcinogenesis induction. One limitation of the method is the sample size that can be collected from the rat's tongue. The area chosen for biopsy did not permit to collect multiple tissue fragments for processing different analytical techniques (eg. immunohistochemistry). Although previous study had shown that few days after tongue punch biopsy may be sufficient for oral mucosal healing (Szpaderska et al., 2003), we did not perform new tissue analysis (inflammation or hormones levels, for example) after the 3 weeks post-biopsy period. Moreover, behavior tests were not performed for analyzing the rats' stress levels, and although we have explored the stress hormones levels in the microenvironment, their receptor-dependent action was not assessed. Systemic corticosterone levels were not evaluate and compared to hormone local concentrations in order to determine whether glucocorticoid effects on carcinogenesis could also represent a stress response.

\section{Conclusions}

This investigation provides the first evidence that pre-carcinogen stress hormones levels in the normal microenvironment can predict chemically induced cancer occurrence. Increased norepinephrine concentrations and reduced corticosterone levels in the tongue microenvironment before oral carcinogenesis induction were predictive for tumor occurrence. Similarly, the predictive effect of norepinephrine was correlated with a lower expression of pCDKN2a-p16 in the tumor microenvironment. BDNF also proved to be an important mediator for oral cancer occurrence. Furthermore, chemical carcinogen may act as an exogenous stressor increasing the stress hormones levels in the microenvironment, which can affect cancer progression. Although they have been observed in a preclinical model, the results of the present study suggest that endocrine individual differences in the normal tissue microenvironment may act as a cofactor of carcinogen modulating the susceptibility to chemically induced tumors.

\section{Conflict of interest}

The authors declare no conflict of interest.

\section{Role of funding service}

This study was supported by the research foundation Coordenação de Aperfeiçoamento de Pessoal de Nível Superior - CAPES/DS; the Psychoneuroimmunology Research Center, Oral Oncology Center,
Department of Pathology and Clinical Propedeutics, Department of Basic Sciences (Araçatuba Dental School, São Paulo State University Unesp); and the Department of Animal Clinic, Surgery and Reproduction (Araçatuba Veterinary Medicine School, São Paulo State University - Unesp).

\section{Acknowledgments}

We thank Dr. Ana Cláudia de Melo Stevanato Nakamune (Department of Basic Sciences, Araçatuba Dental School, São Paulo State University - Unesp) for her help in measuring total protein concentration in the tissue homogenates.

\section{References}

Al-Wadei, M.H., Al-Wadei, H.A., Schuller, H.M., 2012. Pancreatic cancer cells and normal pancreatic duct epithelial cells express an autocrine catecholamine loop that is activated by nicotinic acetylcholine receptors $\alpha 3, \alpha 5$, and $\alpha 7$. Mol. Cancer Res. 10 (2), 239-249.

Anna, B., Blazej, Z., Jacqueline, G., Andrew, C.J., Jeffrey, R., Andrzej, S., 2007. Mechanism of UV-related carcinogenesis and its contribution to nevi/melanoma. Expert Rev. Dermatol. 2 (4), 451-469.

Antoni, M.H., Lutgendorf, S.K., Cole, S.W., Dhabhar, F.S., Sephton, S.E., McDonald, P.G., Stefanek, M., Sood, A.K., 2006. The influence of bio-behavioural factors on tumour biology: pathways and mechanisms. Nat. Rev. Cancer 6 (3), 240-248.

Barnes, L., Eveson, J.W., Reichart, P., Sidransky, D., 2005. World Health Organization Classification of Tumours: Pathology and Genetics of Head and Neck Tumours.

Ben-Eliyahu, S., Yirmiya, R., Liebeskind, J.C., Taylor, A.N., Gale, R.P., 1991. Stress increases metastatic spread of a mammary tumor in rats: evidence for mediation by the immune system. Brain Behav. Immun. 5 (2), 193-205.

Bernabé, D.G., Tamae, A.C., Biasoli, É.R., Oliveira, S.H., 2011. Stress hormones increase cell proliferation and regulates interleukin- 6 secretion in human oral squamous cell carcinoma cells. Brain Behav. Immun. 25 (3), 574-583.

Bernabé, D.G., Tamae, A.C., Miyahara, G.I., Sundefeld, M.L., Oliveira, S.P., Biasoli, É.R., 2012. Increased plasma and salivary cortisol levels in patients with oral cancer and their association with clinical stage. J. Clin. Pathol. 65 (10), 934-939.

Block, T.S., Murphy, T.I., Munster, P.N., Nguyen, D.P., Lynch, F.J., 2017. Glucocorticoid receptor expression in 20 solid tumor types using immunohistochemistry assay. Cancer Manage. Res. 9, 65-72.

Bronzetti, E., Artico, M., Forte, F., Pagliarella, G., Felici, L.M., D'Ambrosio, A., Vespasiani, G., Bronzetti, B., 2008. A possible role of BDNF in prostate cancer detection. Oncol. Rep. 19 (4), 969-974.

Bryne, M., 1998. Is the invasive front of an oral carcinoma the most important area for prognostication? Oral Dis. 4 (2), 70-77.

Chang, J., Xue, M., Yang, S., Yao, B., Zhang, B., Chen, X., Pozzi, A., Zhang, M.Z., 2015. Inhibition of $11 \beta$-hydroxysteroid dehydrogenase type II suppresses lung carcinogenesis by blocking tumor COX-2 expression as well as the ERK and mTOR signaling pathways. PLoS One 10 (5), e0127030.

Chao, M.V., Lee, F.S., 2004. Neurotrophin survival signaling mechanisms. J. Alzheimers Dis. 6 (6 Suppl), S7-11.

Feng, Z., Liu, L., Zhang, C., Zheng, T., Wang, J., Lin, M., Zhao, Y., Wang, X., Levine, A.J., Hu, W., 2012. Chronic restraint stress attenuates p53 function and promotes tumorigenesis. Proc. Natl. Acad. Sci. U. S. A. 109 (18), 7013-7018.

Fitzgerald, P.J., 2009. Is norepinephrine an etiological factor in some types of cancer? Int. J. Cancer 124 (2), 257-263.

Flint, M.S., Baum, A., Episcopo, B., Knickelbein, K.Z., Liegey Dougall, A.J., Chambers, W.H., Jenkins, F.J., 2013. Chronic exposure to stress hormones promotes transformation and tumorigenicity of 3T3 mouse fibroblasts. Stress 16 (1), 114-121.

Hara, M.R., Kovacs, J.J., Whalen, E.J., Rajagopal, S., Strachan, R.T., Grant, W., Towers, A.J., Williams, B., Lam, C.M., Xiao, K., Shenoy, S.K., Gregory, S.G., Ahn, S., Duckett, D.R., Lefkowitz, R.J., 2011. A stress response pathway regulates DNA damage through $\beta 2$-adrenoreceptors and $\beta$-arrestin-1. Nature 477 (7364), 349-353.

Hu, M., Polyak, K., 2008. Microenvironmental regulation of cancer development. Curr. Opin. Genet. Dev. 18 (1), 27-34.

Inbar, S., Neeman, E., Avraham, R., Benish, M., Rosenne, E., Ben-Eliyahu, S., 2011. Do stress responses promote leukemia progression? An animal study suggesting a role for epinephrine and prostaglandin-E2 through reduced NK activity. PLoS One 6 (4), e19246.

Kanojia, D., Vaidya, M.M., 2006. 4-nitroquinoline-1-oxide induced experimental oral carcinogenesis. Oral Oncol. 42 (7), 655-667.

Kupferman, M.E., Jiffar, T., El-Naggar, A., Yilmaz, T., Zhou, G., Xie, T., Feng, L., Wang, J., Holsinger, F.C., Yu, D., Myers, J.N., 2010. TrkB induces EMT and has a key role in invasion of head and neck squamous cell carcinoma. Oncogene 29 (14), 2047-2059.

Lai, P.C., Chiu, T.H., Huang, Y.T., 2010. Overexpression of BDNF and TrkB in human bladder cancer specimens. Oncol. Rep. 24 (5), 1265-1270.

Landen Jr., C.N., Lin, Y.G., Armaiz Pena, G.N., Das, P.D., Arevalo, J.M., Kamat, A.A., Han, L.Y., Jennings, N.B., Spannuth, W.A., Thaker, P.H., Lutgendorf, S.K., Savary, C.A., Sanguino, A.M., Lopez-Berestein, G., Cole, S.W., Sood, A.K., 2007. Neuroendocrine modulation of signal transducer and activator of transcription-3 in ovarian cancer. Cancer Res. 67 (21), 10389-10396.

Lewin, G.R., Barde, Y.A., 1996. Physiology of the neurotrophins. Annu. Rev. Neurosci. 19, 
289-317.

Liggett Jr., W.H., Sidransky, D., 1998. Role of the p16 tumor suppressor gene in cancer. J. Clin. Oncol. 16 (3), 1197-1206.

Lim, A.M., Do, H., Young, R.J., Wong, S.Q., Angel, C., Collins, M., Takano, E.A., Corry, J., Wiesenfeld, D., Kleid, S., Sigston, E., Lyons, B., Fox, S.B., Rischin, D., Dobrovic, A., Solomon, B., 2014. Differential mechanisms of CDKN2A (p16) alteration in oral tongue squamous cell carcinomas and correlation with patient outcome. Int. J. Cancer 135 (4), 887-895.

Lointier, P., Wildrick, D.M., Boman, B.M., 1992. The effects of steroid hormones on a human colon cancer cell line in vitro. Anticancer Res. 12 (4), 1327-1330.

Lowry, O.H., Rosebrough, N.J., Farr, A.L., Randall, R.J., 1951. Protein measurement with the Folin phenol reagent. J. Biol. Chem. 193 (1), 265-275.

Lutgendorf, S.K., Cole, S., Costanzo, E., Bradley, S., Coffin, J., Jabbari, S., Rainwater, K., Ritchie, J.M., Yang, M., Sood, A.K., 2003. Stress-related mediators stimulate vascular endothelial growth factor secretion by two ovarian cancer cell lines. Clin. Cancer Res. 9 (12), 4514-4521.

Lutgendorf, S.K., Lamkin, D.M., Jennings, N.B., Arevalo, J.M., Penedo, F., DeGeest, K., Langley, R.R., 3rd, Lucci J.A., Cole, S.W., Lubaroff, D.M., Sood, A.K., 2008a. Biobehavioral influences on matrix metalloproteinase expression in ovarian carcinoma. Clin. Cancer Res. 14 (21), 6839-6846.

Lutgendorf, S.K., Weinrib, A.Z., Penedo, F., Russell, D., DeGeest, K., Costanzo, E.S., Henderson, P.J., Sephton, S.E., Rohleder, N., Lucci 3rd, J.A., Cole, S., Sood, A.K., Lubaroff, D.M., 2008b. Interleukin-6, cortisol, and depressive symptoms in ovarian cancer patients. J. Clin. Oncol. 26 (29), 4820-4827.

Melamed, R., Rosenne, E., Shakhar, K., Schwartz, Y., Abudarham, N., Ben-Eliyahu, S., 2005. Marginating pulmonary-NK activity and resistance to experimental tumor metastasis: suppression by surgery and the prophylactic use of a beta-adrenergic antagonist and a prostaglandin synthesis inhibitor. Brain Behav. Immun. 19 (2), 114-126.

Muthalif, M.M., Benter, I.F., Karzoun, N., Fatima, S., Harper, J., Uddin, M.R., Malik, K.U., 1998. 20-Hydroxyeicosatetraenoic acid mediates calcium/calmodulin-dependent protein kinase II-induced mitogen-activated protein kinase activation in vascular smooth muscle cells. Proc. Natl. Acad. Sci. U. S. A. 95 (21), 12701-12706.

Nilsson, M.B., Armaiz-Pena, G., Takahashi, R., Lin, Y.G., Trevino, J., Li, Y., Jennings, N., Arevalo, J., Lutgendorf, S.K., Gallick, G.E., Sanguino, A.M., Lopez-Berestein, G., Cole, S.W., Sood, A.K., 2007. Stress hormones regulate interleukin-6 expression by human ovarian carcinoma cells through a Src-dependent mechanism. J. Biol. Chem. 282 (41), 29919-29926.

Ottaviani, E., Franchini, A., Genedani, S., 1999. ACTH and its role in immune-neuroendocrine functions. A comparative study. Curr. Pharm. Des. 5 (9), 673-681.

Pyter, L.M., Prendergast, B.J., 2013. Individual differences in pre-carcinogen cytokine and corticosterone concentrations and depressive-like behavior predict tumor onset in rats exposed to a carcinogen. Psychoneuroendocrinology 38 (6), 800-807.

Reiche, E.M., Nunes, S.O., Morimoto, H.K., 2004. Stress, depression, the immune system, and cancer. Lancet Oncol. 5 (10), 617-625.

Rich, T., Innominato, P.F., Boerner, J., Mormont, M.C., Iacobelli, S., Baron, B., Jasmin, C., Lévi, F., 2005. Elevated serum cytokines correlated with altered behavior, serum cortisol rhythm, and dampened 24-hour rest-activity patterns in patients with metastatic colorectal cancer. Clin. Cancer Res. 11 (5), 1757-1764.

Saloman, J.L., Albers, K.M., Rhim, A.D., Davis, B.M., 2016. Can Stopping nerves stop cancer? Trends Neurosci. 39 (12), 880-889.

Saruta, J., Lee, T., Shirasu, M., Takahashi, T., Sato, C., Sato, S., Tsukinoki, K., 2010. Chronic stress affects the expression of brain-derived neurotrophic factor in rat salivary glands. Stress 13 (1), 53-60.

Smit, M.A., Geiger, T.R., Song, J.Y., Gitelman, I., Peeper, D.S., 2009. A Twist-Snail axis critical for TrkB-induced epithelial-mesenchymal transition-like transformation, anoikis resistance, and metastasis. Mol. Cell. Biol. 29 (13), 3722-3737.

Sood, A.K., Bhatty, R., Kamat, A.A., Landen, C.N., Han, L., Thaker, P.H., Li, Y., Gershenson, D.M., Lutgendorf, S., Cole, S.W., 2006. Stress hormone-mediated invasion of ovarian cancer cells. Clin. Cancer Res. 12 (2), 369-375.

Szpaderska, A.M., Zuckerman, J.D., DiPietro, L.A., 2003. Differential injury responses in oral mucosal and cutaneous wounds. J. Dent. Res. 82 (8), 621-626.

Thaker, P.H., Han, L.Y., Kamat, A.A., Arevalo, J.M., Takahashi, R., Lu, C., Jennings, N.B., Armaiz-Pena, G., Bankson, J.A., Ravoori, M., Merritt, W.M., Lin, Y.G., Mangala, L.S., Kim, T.J., Coleman, R.L., Landen, C.N., Li, Y., Felix, E., Sanguino, A.M., Newman, R.A., Lloyd, M., Gershenson, D.M., Kundra, V., Lopez-Berestein, G., Lutgendorf, S.K., Cole, S.W., Sood, A.K., 2006. Chronic stress promotes tumor growth and angiogenesis in a mouse model of ovarian carcinoma. Nat. Med. 12 (8), 939-944.

Tsukinoki, K., Saruta, J., 2012. Role of stress-related brain-derived neurotrophic factor (BDNF) in the rat submandibular gland. Acta Histochem. Cytochem. 45 (5), 261-267.

Warnakulasuriya, S., Johnson, N.W., van der Waal, I., 2007. Nomenclature and classification of potentially malignant disorders of the oral mucosa. J. Oral Pathol. Med. 36 (10), 575-580.

Xie, H., Li, C., He, Y., Griffin, R., Ye, Q., Li, L., 2015. Chronic stress promotes oral cancer growth and angiogenesis with increased circulating catecholamine and glucocorticoid levels in a mouse model. Oral Oncol. 51 (11), 991-997.

Yang, Z.F., Ho, D.W., Lam, C.T., Luk, J.M., Lum, C.T., Yu, W.C., Poon, R.T., Fan, S.T., 2005. Identification of brain-derived neurotrophic factor as a novel functional protein in hepatocellular carcinoma. Cancer Res. 65 (1), 219-225.

Yang, E.V., Sood, A.K., Chen, M., Li, Y., Eubank, T.D., Marsh, C.B., Jewell, S., Flavahan, N.A., Morrison, C., Yeh, P.E., Lemeshow, S., Glaser, R., 2006. Norepinephrine upregulates the expression of vascular endothelial growth factor, matrix metalloproteinase (MMP)-2, and MMP-9 in nasopharyngeal carcinoma tumor cells. Cancer Res. 66 (21), 10357-10364.

Ye, Y., Dang, D., Zhang, J., Viet, C.T., Lam, D.K., Dolan, J.C., Gibbs, J.L., Schmidt, B.L. 2011. Nerve growth factor links oral cancer progression, pain, and cachexia. Mol. Cancer Ther. 10 (9), 1667-1676.

Yu, X., Lu, L., Liu, Z., Yang, T., Gong, X., Ning, Y., Jiang, Y., 2016. Brain-derived neurotrophic factor modulates immune reaction in mice with peripheral nerve xenotransplantation. Neuropsychiatr. Dis. Treat. 12, 685-694.

Zhu, Z., Jiang, W., Thompson, H.J., 2003. Mechanisms by which energy restriction inhibits rat mammary carcinogenesis: in vivo effects of corticosterone on cell cycle machinery in mammary carcinomas. Carcinogenesis 24 (7), 1225-1231.

van der Waal, I., Schepman, K.P., van der Meij, E.H., Smeele, L.E., 1997. Oral leukoplakia: a clinicopathological review. Oral Oncol. 33 (5), 291-301. 